\title{
Memoria de Dios y otros poemas
}

\author{
Torna a cobrar el tino
}

y memoria perdida

de su origen primera esclarecida

(Fr. Luis de León: A Francisco Salinas).

I

Brilla la comba fúlgida del cielo

de azul inviolado y transparente.

Y la luz invasora, llaga ardiente, se derrama a raudales por el suelo.

El sol, ave en la cima de su vuelo, hiere el valle con su pico ciegamente.

Sueña el agua dormida bajo el puente;

la alameda me da su umbrío velo.

$\mathrm{Y}$ es música y aroma, embriagadora

delicia, que me arrastra vencedora;

llamarada que suave se traspasa

a la profunda noche de mis minas, donde se funde con la oculta brasa

y el sol de eternidad de mis colinas.

\section{II}

Me trae, ¡oh Dios!, el triunfo del verano testimonio de tu huella en las cosas, cuando tus dedos heñían nebulosas y trazabas linderos con tu mano. 
Me lo dice la brisa de este llano;

me lo canta el perfume de las josas

y la armonía exacta de las rosas

y el violín del jilguerillo ufano.

Hermanados frutos, valles, oteros, ríos, chopos, estrellas, ventisqueros cantan, sujetos a norma, tu gloria.

Todo vibra perfecto en la hermosura del mundo. Tengo impresa tu figura $\mathrm{y}$ aroma de tu paso en la memoria.

\section{LA POESÍA}

A mis alumnos del curso 1963-1964.

Vengo detrás de una copla

que había por el sendero

(Juan Ramón Jiménez)

La otra tarde, en el estudio, por los senderos del sueño buscando mariposas de luz os he visto.

Por mucho que las sigáis, no les daréis alcance.

Es el destino nuestro:

seguir, seguir tras la belleza, errante por los caminos, con el corazón herido, sangrante, sin paz en los huesos.

Es una canción lejana, aroma de rosas invisibles, la voz que oímos en sueños, guiño seductor de estrellas deslumbrantes, ¡blancas!, ¡blancas! 
Iréis a cogerla

y huirá más lejos;

pero el corazón,

anhelante,

seguirá el rastro aromado,

siempre,

siempre horadando hacia el misterio.

\section{SI YO ESCRIBIERA VERSOS}

A Dámaso Alonso, maestro de maestros, con mi recuerdo hecho plegaria.

Si yo escribiera versos, diría sin rodeos,

llanamente,

el tantear del hombre en la tiniebla en busca de la luz;

su grito isleño

de náufrago, que clama por la orilla

donde vive la dicha renovada.

Y cómo, siempre tensas,

sus fuerzas misteriosas

(espíritu concentre

o indague la razón del trazado del mundo,

su entraña reduciendo a fórmulas y leyes;

busque pan o verdad busque)

hacia la única diana apuntan anhelantes:

cielo y tierra dirigen hacia Dios

la inquietud de sus flechas.

Hombre de Dios soy.

$\mathrm{Y}$ el temblor milagroso de mi vida

y la onda fugitiva de mi palabra

el flujo son de su marea,

que se hace en mí cauce limitado,

a escala humana.

Me asomo a su corriente

y en su fanal parpadeante veo

mi propia figura, reflejo de la suya creadora, 
vida creando,

a impulsos de su aliento animador, y la imagen lustrada de las cosas, libres de la torpe ramazón que las encubre a la mirada, revelando sus ansias más secretas, todas hermanadas.

Hombre es red inextricable de tiernas relaciones; urdimbre entretejida, minuto tras minuto, por la rauda lanzadera de los años.

Si se desata, se deshace en hilachas de desganas o de cansancios tristes.

Hombre es tierra

donde anudan sus raíces muchedumbre de savias.

Arrancadlas, y es páramo donde mugen los vientos negramente agoreros.

Hombre es cruce de crujientes pulpas, donde en amor se encuentran Dios y las obras modeladas por sus manos.

Si yo escribiera versos, iría al hombre, a descifrar su enigma, a arrancar su antifaz, su costra de artificio; a azuzar sus enjambres ateridos de frío. Prendería una llama en las últimas celdillas de su vida para ver -costumbre siempre nuevaborbollar su colmena con dulce, vahariento zumbido.

Sus afanes, abejas; el romeral, Dios.

\section{A RAS DE TIERRA}

A ras de tierra mi canto, mi verso no tiene vuelo. ¿Para qué, si a nadie gusta que le distraigan del juego, 
ni las cartas boca arriba le pongan, ni el saboreo del limón verdiagridulce de la verdad en sus dentros? Amor, servicio, hermandad... Siga la farsa, dancemos. Iglesia, Cristo, las almas... gritemos de mentira ebrios. Palabras, solo palabras, palabras que lleva el viento. A ras de tierra mi canto, mi verso no tiene vuelo. Palabras, también palabras. Quiero callar y no puedo. Quisiera encontrar vocablos de marfil, neutros, sin fuego; dar a mi verso blancura, frío de escarcha en enero; pero se me encrespa rojo de sangre bullente, férvido. $\mathrm{Y}$ restalla como un látigo sobre tanto fariseo.

\section{VERANILLO DE SAN MARTÍN}

¡Envuelta en tocas de bruma, la nieve de Peña Ubiña!

Sus cumbres de azul y rosa, al sol que asoma, se pintan. Aquí, cerca, en los recodos el río pasa revista a los chopos centinelas, que en la mañana buida mantienen su guardia a pie firme, desnudas las picas. Tablares de sembradura despereza la luz niña, que curiosea la huerta y escala tapias caídas. 
En los rodales de césped, deslumbrante escarcha nítida. Bajo el cielo azul turquesa, se ha quedado sorprendida y encandilada la luna; y de la aldea tranquila humean las chimeneas. ¡Vivir! ¡Vivirse! ¡Alegría! iSalir, salir por el campo hacia la gloria del día! ¡Exaltarse en plenitudes! ¡Estar en paz y armonía con el mundo! ¡Sus! ¡Y arderse en los soles de la vida!

\section{NIEVE AL AMANECER}

El cielo, sin una estrella, se arropó con su bufanda de nubes. Lenta la nieve caía borrando aristas -mano que todo lo iguala-. Con la nieve el caballito de la cellisca jugaba; jugaba haciendo corvetas, la echaba contra las tapias. Al alma, niña de un día, le iban naciendo las alas, y el torrente de sus penas ya era hoyuelo de agua clara. Se retiraban los miedos, amanecía en la casa; allá en el fondo del bosque, los lobos ya no le aullaban. 


\title{
TRÉBOL
}

\author{
¡Ay de vosotros! \\ Porque siempre os faltará tiempo \\ de ver las nubes, \\ grises corderos \\ por la azulada \\ y alta pradera de los cielos. \\ No dormiréis nunca en el soto \\ oyendo el susurrar del viento, \\ ni en la mañana luminosa \\ os perderéis por los senderos. \\ Os cegarán con el cascote \\ de los secos libros de texto.
}

¡Ay de vosotros!

No tendréis tiempo para el sueño, para soñar por los caminos

del alma, a la luna de enero, cuando el silencio profundiza y hay sementera de luceros.

La caverna interior se enciende, alumbrada por rojo fuego.

Todo gime; la paramera siente la llamada del cielo; y se oye pura

la voz de Dios, que canta dentro.

Ninguna flor se asomará

a vuestro pozo siempre seco.

¡Ay de vosotros!

Os dirán los libros de texto que es la tierra la que se mueve y que es mentira el nacimiento del sol, cuando enciende su hoguera, despereza y alegra el suelo;

y mentira, cuando cansado

se reclina sobre los cerros;

que el hombre es células, un ente, moléculas en hervidero; 
que el alma es principio de vida; y Dios motor sin movimiento, que empuja la potencia al acto (lo dicen los libros de texto).

¡Ay de vosotros!, si no dejáis el saber ciego de bachilleres

que se han quedado sin el tuétano; si no retornáis al asombro aquel de los días primeros; si no os arrastra la llamada de los valles hondos, repuestos, del alma y vais por sus veredas como va la cabra al codeso; si no os sentís estremecidos, hundiendo en el río los dedos; si no os sentáis junto al espino, a oír los mensajes secretos que envía a estrellas lejanas, en armonía con el vuelo de las palomas;

si del hombre de carne y hueso no os sentís amigos y hermanos y eleváis por él vuestros rezos; si no trabajáis con él unidos, puesta la vela a un mismo viento.

¡Ay de vosotros!, si en la luz auroral del verso no sabéis envolver el mundo, desvelando matices nuevos; si no sabéis dar a las cosas su gozo eterno de criaturas recién hechas, trasladadas a un mundo pleno; si en el fervor de la palabra -río que fluye siempre llenono sabéis derramar vuestra alma y vuestro corazón entero. 
¡Ay de vosotros!,

si, en medio del montón de ruinas

-eso son los libros de texto-,

gráciles, rientes,

no ponen su verdor de ensueño

las tres hojitas temblorosas

de algún trébol que os nazca dentro.

\section{PAN DE VIDA}

«La verde oliva ansí nos resplandece

y el pan da valentía

(Fr. Luis de León: Traducción del Sal 104, (103), v. 15.

Se entra el agua, cantando, en el molino

hacendosa, harinera;

gira la piedra, fiel a su destino, y el trigo rubio espera,

triturado, salir en flor de harina.

El pan de valentía,

que pujante crecía en la colina,

en la llanada umbría,

en la vega..., y era amor de la brisa,

porque Dios lo ha querido

se ofrenda por mis manos en la misa, en Cristo convertido.

Las espigas dispersas se han aunado

en albura de nieve.

Pan blanco, nuevo Pan, anonadado, a buen fruto nos mueve.

Y florecen las mieses candeales, si el alma es tierra buena;

y son un solo cuerpo los mortales

que toman esta cena.

Si la semilla que el labrador entierra no muere, sola queda. 
Mas este Pan durmió bajo la piedra y aquí se nos entrega.

Hostia, que al alma vienes deseosa de dar muerte a la muerte, mete a cuchillo mi vejez añosa.

$\mathrm{Y}$ así podré ofrecerte

el alma limpia y pura y traspasada, panecillo de luz.

Di: ¿qué senda nos lleva a esa alborada?

- La senda de la cruz.

\section{MUJER}

\section{A María Celia González Fuentes, al cumplir quince años.}

Llegó tu primavera.

Mejor: te está llegando.

Florido el cuerpo grita el empuje del árbol de la vida, pimpante de hermosura, esplendoroso, musical, alado.

En tu mirada, hondura del mañana que se viene con paso presuroso; negra tu cabellera da sombra al entusiasmo que irradia de tu rostro, claro, profundo lago; $y$ bullen en tu frente las ideas con el brillo y misterio de los astros.

Y son luz y son noche y son risa y son llanto y son un horizonte de esperanzas $y$ un camino cerrado en que a veces te pierdes, hecha un lío, sin encontrar salida al ancho campo. 
Es tiempo de vivir.

Vive con gozo; que, al vivir, logramos

ser, ser más, hacernos en el complejo

y sutil entramado

que nos une con nuestra circunstancia.

Goza de la amistad; ensancha el radio

de acogida; disfruta del paisaje,

de la luz, de la brisa y de los astros.

Que el sol del arte inunde

y Dios - vivimos libres en sus manostu corazón de música y belleza.

Coge las rosas, que huye el día raudo.

\section{LAS PRESAS DEL TERA}

Fue una noche de invierno. ¿De enero? Salí de casa contigo a llevar la cena al pastor. Se escuchaba el silencio. Al doblar la calle, mitad en sombra, mitad alumbrada de luna llena, se oía un rumor intenso. «iQué bien se oyen las presas del Tera!», me dijiste: «¡vaya manta que está cayendo!».

Era un fanal la noche.

Los puñales buídos del relente se clavaban en los manzanos ateridos y en el prado acurrucado de silencio.

Arriba, el cielo azul, azul limpísimo, como una inmensa comba que manos invisibles manejaran

a uno y otro extremo del horizonte y se hubiera quedado quieta, eternamente quieta, en el punto más alto, inútil para el juego. 
Como un pan recién hecho, la blanca luna llena

paseaba su asombro por el pueblo, enjalbegando tapias y tejados, mientras dejaba media calle en sombra.

Enardecido parpadeo de innumerables velas recordaba la infantil cantilena aprendida en la escuela, el desafío de Dios a Abrahán, padre de pueblos: sal al campo y cuenta las estrellas, si puedes.

Rejas de claridad sus rayos eran $\mathrm{y}$ hondos surcos en mi alma, sin yo enterarme, abrían.

En el recogimiento del pueblo ensimismado, (la vida, en los hogares, al amor de la lumbre; donde -en trébedes o en llaresse aliñaba o cocía lenta la cena de hombres y animales) solo se oía, musical, invasor, horadante, el rumor incansable de las presas del Tera; del agua que, al hurtarse entre las peñas, caía, espuma hecha, contra lúbricos guijarros estrellada.

$Y$, a veces, intenso se acercaba y apagado, a veces, se alejaba.

Transverberado, poseído, el cuerpo se hizo música y silencio

y luz y estrella y agua

$y$ relente y fuego y casa

y huerto y cielo y prado

y pueblo

y pueblo

y pueblo. 
¡Instante eterno! ¡Ancla del tiempo!

(Así a Agustín,

una noche en que estaba desvelado, el ruido intermitente del agua despeñada

le sacó de sí mismo y dejó absorto,

en un tiempo sin tiempo,

en éxtasis,

en vilo,

para luego inquirir sobre las causas

de tan raro fenómeno,

discurriendo sobre el ritmo y el orden.

Así Fr. Luis,

sentado a la vera de un arroyo

formado por el agua que

cáía

de la presa

de unas aceñas,

con sus amigos platicaba sobre la paz y el orden, transportado

-alta ya la noche sembrada de estrellas

y otro cielo estrellado el río hecho-,

mientras la voz del agua crecía en el silencio.

Noche de «miedos veladores»

-le nacen al miedo cien mil ojos-, aquella en que Sancho y don Quijote, recogidos en un soto, escucharon temerosos

el estruendo confuso de un buey de agua

y el seco golpear de unos batanes.

Séame permitido

recordar experiencias tan excelsas

al hilo de la mía,

tierna, mínima;

salvarla del olvido ennoblecida).

Rumor que se adentró

por la cava más honda

de los más hondos fosos de mi alma. 
Y ahí está,

dando vida a mi verso y alma a mi palabra.

Como el tuero inextinguible

(o leño trashoguero)

conserva vivo el fuego.

¡Noche alta de enero,

la noche aquella de luna y música y silencio

y de estrellas y escarcha

y campo y agua y pueblo!

En mi alma te tengo, noche santa

- «amable más que la alborada»;

ahí te tengo y te veo.

Tú eres el cimiento profundo de mi casa, la oculta savia de mis arboledas, la luz de mis secretos corredores, mi huelgo de hombre;

la raíz que, saliendo de la entraña de la tierra, hacia flores y frutos puja y puja.

Tú eres el vivo manantial perenne que da agua a mis acequias;

ventalle de mis huertos, que lleva su perfume a las estrellas.

Y eres tú, rumor del Tera, mi música más honda y luminosa, mi pulso y voz y canto.

Tú, fugitivo río eterno, «tan antiguo y $\tan$ nuevo», tú modulas mis versos -tu estrofa es mi estrofay les fijas su ritmo y su acento y su número de oro. 


\title{
NANAS DE MARÍA A JESÚS, NIÑO
}

\author{
A Berta Puga Fuentes,
} en su primera comunión.

Duérmete, Jesusito, sobre mi hombro; que la noche ya viene y aúlla el lobo.

Duérmete, niño mío, junto a mis pechos. Las estrellas se miran en tus ojuelos.

Duérmete, ángel mío, entre mis brazos.

Ya sosiega la brisa la voz y el paso.

Duérmete, nazareno.

Nazaret duerme; sola la fuente llora, su pena mece.

Duérmete, racimico, bien de mi vida.

El pan y el vino duermen en las colinas.

Duérmete, Manolito, luz de mis ojos.

Mira que, si no duermes, llamaré al coco.

Duérmete, sueño mío, Dios de mi alma.

Ya mi niño se duerme; duerme y descansa.

Dentro, mi niño, te llevo, muy adentro, ¡Crezco contigo! 